\title{
South Sudan
}

National Cancer Institute

\section{Source}

National Cancer Institute. South Sudan. NCI Thesaurus. Code C97351.

A country in east central Africa south of Sudan, north of Uganda and Kenya, and west of Ethiopia. 